\title{
Kolonun benign anastomoz darlığında rektal mesalazin tedavisi sonrası endoskopik balon dilatasyonu
}

\author{
Endoscopic balloon dilatation after rectal mesalazine treatment within an uncertainty of colonic \\ anastomosis
}

Enver AKBAŞㄴ, Serkan ÖCAL², Abdullah Emre YILDIRIM², Reskan ALTUN², Murat KORKMAZ², Haldun SELÇUK²

${ }^{1}$ Istanbul Medipol Üniversitesi Tip Fakültesi, Gastroenteroloji Kliniği, Istanbul

${ }^{2}$ Başkent Üniversitesi Tip Fakültesi, Gastroenteroloji Kliniği, Ankara,

\begin{abstract}
Anastomoz darlikları kolorektal cerrahinin bilinen bir komplikasyonu olmasina rağmen benign hastalıklarda komplet kolonik anastomoz obstrüksiyonu nadirdir. Benign darliklar low-anterior rezeksiyon sonrası yapılan kolorektal anastomozda nispeten sik görülen bir komplikasyondur ve kolorektal anastomozlarm \%5-22'sinde gelişebilir. Günümüzde benign anastomoz darlıklarının tedavisinde ilk seçenek endoskopik girișimlerdir. Ceșitli endoskopik teknikler tarif edilmesine rağmen optimal yaklaşım için kontrollü prospektif çalışma verileri eksiktir. Bu çalışmada ileri derecede anastomoz darlığı gelişmiş ve endoskopik balon dilatasyon uygulanan bir hastanın sunulması amaçlandı. Hastaya bir haftalık rektal mesalazin tedavisinden sonra bir kez ayaktan balon dilatasyonu uyguland ve darlık giderildi. Rektal mesalazin uygulamasının darlık bölgesindeki inflamutuvar sürece olumlu etkisi oldu ve balon dilatasyon sayısını azalttı. Kolorektal darlıklarm tedavisinde endoskopik balon dilatasyon 1985'ten beri kullanılmaktadır. Minimal invaziv bir yöntemdir, başarı oranı yüksektir, güvenle direkt görüş altında yapılabilir, tekrarlanabilir ve hastanede yatıs gerektirmez.
\end{abstract}

Anahtar kelimeler: Kolon anastomoz darlığı, mesalazin, kolon balon dilatasyonu

\section{GİRISs}

Benign striktürler kolonik anastomozların nisbeten sık görülen bir komplikasyonudur ve vakalarm \%5-22'sinde meydana gelebilir (1). Sriktürlerin dilatasyonu klinik olarak önemli fonksiyon bozukluğu varlığında veya tanı ya da tedavi amacıyla darlığın ötesine geçmek gerektiğinde yapılır (2). Stenozlar kalın barsağın diğer anastomozlarıyla kıyaslandığında kolorektal anastomozlarda daha sıktır (3). Benign anastomoz darlıklarının nedeni hala tam olarak anlaşılamamasına rağmen iskemi, açllma ve radyasyon tedavisi sorumlu tutulmaktadır $(4,5)$. Hastaların çoğunda, anastomoz darlığı, tekrarlayan endoskopik girişim veya cerrahi tedavi gerektiren ciddi bir durumdur. Bunun için farklı teknikler önerilmesine rağmen kolonoskopi ile müdahale hala ilk tedavi seçeneğidir. Skopi aracıllğı ile balon dilatasyonu bize kolay uygulanabilir bir müdahale seçeneği sunar. Uzun dönem prospektif çalışma verileri olmamasına rağmen endoskopik balon dilatasyonu ile postoperatif kolonik darlıkların tedavisi ilk tanımlandığı
Although anastomotic strictures are a recognized complication of colorectal surgery, complete colonic anastomotic obstruction from benign disease is rare. A benign stricture is a relatively common complication of colorectal anastomosis after low anterior resection and may develop colonic anastomosis in 5\%-22\% of cases. Today, endoscopic interventions have become the preferred first-line treatment for postoperative large bowel strictures. A variety of endoscopic techniques have been described, but there is a lack of data from controlled prospective trials regarding the optimal approach. In this study, a case of severe anastomotic stricture of the colon, during which endoscopic balloon dilatation was performed, is presented. After a one-week course of treatment with rectal mesalazine, the ambulatory patient underwent balloon dilation only once and the stricture resolved. Rectal mesalazine administration had a positive effect on the inflammatory process at the site of stenosis and reduced the number of balloon dilatations. Endoscopic balloon dilatation has been used since 1985 for the treatment of colorectal strictures. It is a minimally invasive method, has a high success rate, can be performed safely under visual control, can be performed repeatedly, and does not require hospitalization.

Key words: Colonic anastomosis stenosis, mesalazine, colonic balloon dilatation

1984 'ten beri güvenle ve etkili olarak yapılmaktadır $(6,7)$. Bizim çalışmamızda rektum karsinomu nedeniyle opere edilen ve postoperatif anastomoz darlığı gelişen hastada bir haftalık rektal mesalazin tedavisi sonrası bir kez uygulanan endoskopik balon dilatasyonu ile darlığın tamamen giderilmesi ve yeterli pasajın sağlanmasını sunmayı amaçladık.

\section{OLGU SUNUMU}

Altmış dört yaşında erkek hastaya yaklaşık 2 yıl önce rektumda anal kanala 7-8 cm mesafedeki adenokarsinom nedeniyle low-anteror rezeksiyon ve kolorektal anastomoz uyguland. Karaciğer sağ lob anterior segmentte yaklaşık $15 \times 12$ mm boyutlarında hipodens lezyon izlenen hastaya yapilan lezyon biyopsisi adenokarsinom metastazı gelmesi üzerine bu lezyona da intraoperatif radyofrekans (RF) ablasyon tedavisi uygulandi. Daha sonrasında 6 kür kemoterapi verildi. 
Operasyondan 20 gün sonra kolonda anastomoz kaçağı gelişmesi üzerine segmenter ince barsak rezeksiyonu ve ileostomi uygulandı. Daha sonra ileostomisi kapatıldı. Operasyondan yaklaşık 12 ay sonra cildde kesi yerinden fekal karakterde sızıntı olması üzerine yeniden laparotomi yapılan hastaya kolostomi açıldı.

Operasyondan 19 ay sonra yapilan endoskopik incelemede anastomoz hattına yakın polipoid oluşumdan alınan biyopsi patoloji tarafından iltihabi eksuda, yoğun aktif kronik iltihabi granülasyon dokusu olarak rapor edildi, tümör nüksü saptanmadi.

Hastanın kolostomisinin kapatılması planlandığı için yapılan kontrol kolonoskopide rektum 8 cm'de anastomoz darlığı tespit edildi. Darlık çevresinde nöbetçi inflamatuvar polibin de olduğu hiperemik, ödemli ve inflame mukoza mevcuttu. Kolonoskop ve endoskopi ile denenmesine rağmen yukarıya geçilemedi. Nelaton sonda ile darlığın proksimaline geçildi ve buradan opak verilerek barsağın görüntülenmesi planlandı. Buradan ve kolostomiden verilen opak madde sonrası alınan skopi görüntülerinde kolonik fistül saptanmadı.

Hastaya 1 haftalık rektal mesalazin $250 \mathrm{mg} 2 \mathrm{xl}$ dozunda verildi ve sonrasında yapılan kolonoskopide nöbetçi inflamatuar polibin kaybolduğu, ödem ve inflamasyonun gerilediği gözlendi. Rektumda izlenen fibrotik darlık 20 mm özofagus dilatasyon balonu ile dilate edildi. İşlem sonrası komplikasyon olmadi.

Bu işlemden 5 gün sonra rektumdan kolonoskop ile girilerek $8 \mathrm{~cm}$ kadar ilerlendi, bu mesafedeki darlık geçilerek kolon boyunca ilerlendi ve kolostominin cilt ağzına kadar gelindi, lümen ve mukoza normal idi. Darlık mesafesindeki inflamasyonun kaybolduğu görüldü.

\section{TARTISMA}

Benign anastomoz darlıkları low-anterior rezeksiyon yapılan hastaların \%5-22'sinde gelişebilir. Weinstock ve Shatz, kolon neoplazmı nedeniyle rezeksiyon yapılan hastalarda anastomoz anormallikleri için yaptıkları endoskopik bir çalışmada 11 ylllık izlemde \%0.5 anastomoz darlığı geliştiğini bulmuşlar (2). Luchtefeld ve ark.'nın 123 anastomoz darlıklı hastada yaptıkları araştırmada obezite ve apse oluşumu preoperatif risk olarak belirlenmiş (4). Postoperatif anastomoz kaçağl, pelvik infeksiyon ve postoperatif radyasyonun katkıda bununan faktörler olduğuna inanılmaktadır. Chung ve arkadaşları hayvan modelinde yaptıkları bir çalışmada anastomoz darlıklarının patogenenezinde doku iskemisinin rolüne dikkat çekmișlerdir (5). Low-anterior rezeksiyon sonrası anastomoz darliğı olan hastaların tümünde semptom olarak konstipasyon, karın ağrısı ve inkontinans vardır. Cerrahi tedavi seçeneği rezeksiyon ve reanastomozdur ama yüksek morbidite ve önemli mortalite oranları vardır. Anastomoz darlıklarının tedavisinde kullanılan çok değişik endoskopik teknikler vardır. Bunlardan ilk kullanılanı buji ile dilatasyon metodudur. Dilatasyon aksiyal bir kuvvet uygulayan bir radyal vasıtasıyla sağlanır (8). Werre ve arkadaşları low-anterior rezeksiyon sonrası bening striktürlerin dilatasyonunu "polyvinil buji" kullanarak yapmışlar ve 15 hastanın 10'unda normal defekasyon sağlamışlardır. 5 hastada kısmi düzelme sağlanırken, sadece 3 hastada diğer tedavi formlarına ihtiyaç duyulmuş. Komplikasyon meydana gelmemiş (9). Pietropaolo ve ark.'nın vaka sunumunda balon dilatasyonu buji dilatasyonundan daha etkili bulunmus, tek seansta tedavi edilen hastaların başarı oranları sırasıyla \%76 karşın \%51 imiş (10). Balon dilatatörler ile bütün dilatasyon kuvveti radyal olarak oluşur ve böylece makaslama gerilimi önemli derecede azalır. Balon dilatasyonu ile çevresel ve radyal olmak üzere iki kuvvet uygulanır ve her ikisi de balon çapı ile artar. Dilatasyonda iki tip balon kullanılabilir; OTW ve TTS. OTW tekniği ile balon çapı daha fazladır ve daha fazla dilatasyon kuvveti uygulanabilir. Yapılan çalışmalarda, kolonik anastomoz darlıkları için balon dilatasyonunda \%86 ile \%97 arasında başarı oranları bildirilmiştir (11-14). Fakat bu çalışmalar kontrolsüz çalışmalar olup hasta sayıları azdır ve takip süreleri kısadır. Hagiwara ve ark. low-anterior rezeksiyon sonrası anastomoz darlığı gelişen 5 hastada yaptıkları insizyon ve balon dilatasyonu kombinasyonu ile \%100 başarı ve sıfır komplikasyon bildirmişlerdir. Hastalarda 15-20 dakikalık balon dilatasyonunu takiben endoskopik görüş altında striktür bölgesine elektrokoter ile üç küçük insizyon yapılmış (15). Luck ve arkadaşları 10 hastaya "neodymium-yttrium aluminum garnet lazer" kullanarak endoskopik striktürotomi ile birlikte balon dilatasyonu uygulamışlar. Tedavi 9 hastada komplikasyon ve rekürrens olmaksızın başarılı olmuş. Ortalama izlem süresi ise 82 ay imiş. Kalan 1 hastada striktür 6 yll sonra tekrarlamış (16). Brandimarte ve ark. kolorektal anastomoz darlığı olan 39 hastada endoskopik görüş altında pre-cut papilotom ile 6 radyal insizyon yapmışlar. Bütün vakalarda komplikasyon olmaksızın yeterli dilatasyon sağlanmıs ve ortalama 25 aylık izlemde rekürrens gözlenmemiş (17). Virgilio ve ark. 17 hastada 30-40 mm çapında akalazya tedavisinde kullanılan pnömatik balon dilatatörleri kullanmışlar. 5 hastaya bir seans, 8 hastaya 2 seans ve kalan 4 hastaya ortalama 4.5 seans balon dilatasyonu uygulanmış. Uzun süreli iyi sonuçlar 16 hastada sağlanmış. 2 hastada komplikasyon (perforasyon ve geçici mukozal kanama) meydana gelmiş (7).

Bir çalışmada ise $18 \mathrm{~mm}$ TTS balon ve akalazya tedavisi için tasarlanmış $35 \mathrm{~mm}$ OTW balon olmak üzere iki tip dilatatör kullanılmış. Her iki teknik de kolay uygulanır ve güvenli imiş, her iki grup hastada iyi sonuçlar elde edilmiş. Fakat OTW grubunda önemli derecede daha az sayıda dilatasyon gerekmiş ve dilatasyon süresi daha uzunmuş. Bu sonuçlar 35 mm balonun çapının daha büyük olması nedeniyle daha fazla çevresel ve radyal kuvvet uygulamasına bağlanmıs. 
Anastomoz darlıklarının tedavisinde propofol anestezisi kullanılması önerilir ve skopi kullanılması özellikle uç-yan anastomozlarda kılavuz telin doğru yerleştirilmesi için zorunludur. Kilavuz tel, eğer darlık pediatrik kolonoskop veya endoskopun geçişine izin veriyorsa skopi olmadan da yerleştirilebilir. Genel olarak low-anterior rezeksiyon sonrası kolorektal anastomoz darlıklarının dilatasyonu TTS balon ile kıyaslandığında OTW pnömatik balon ile daha güvenlidir ve daha iyi sonuçlar elde edilmiştir.

Kolon cerrahisi sonrası gelişen anastomoz darlıklarının tedavisinde bir takım yeni tekniklerle yapılan çalışmalar da bildi- rilmesine rağmen $(18,19)$ pnömatik balon dilatasyonu hala en güvenilir, en emniyetli ve kolay uygulanabilir bir yöntemdir. Fakat endoskopik balon dilatasyonu uygulanan hastaların ancak \%30-40'ında bir seansın yeterli olduğu ve her hasta için ortalama 2.4 seans gerekli olduğu bildirilmektedir $(20,21)$. Bizim hastamızda anastomoz bölgesindeki inflame ve ödemli görünüm ve inflamatuvar polipoid oluşum nedeniyle bir hafta süreyle rektal mesalazin verilmesinin olumlu etkisinin olduğu kanaatindeyiz. Bir kez kolon balonu ile dilatasyondan 3 gün sonra endoskopun, 7 gün sonra da kolonoskopun geçişine izin veren yeterli pasaj açıklığı sağlandı. Hastada herhangi bir komplikasyon olmadi.

\section{KAYNAKLAR}

1. Geller A, Gal E. Dilation of benign strictures following low anterior resection using Savary-Gilliard bougies. Endoscopic treatment of benign anastomotic colorectal stenosis with electrocautery. Gastrointest Endosc. 2001;54:277-279.

2. ASGE Technology Committee Tools for endoscopic stricture dilation. Gastrointest Endosc. 2004;59:753-760.

3. Luchtefeld MA, Milsom JW, Senagore A, et al. Colorectal anastomotic stenosis. Results of a survey of the ASCRS membership. Dis Colon Rectum. 1989;32:733-736.

4. Chung RS, Hitch DC, Armstrong DN. The role of tissue ischemia in the pathogenesis of anastomotic stricture. Surgery. 1988;104:824-829.

5. Polglase AL, Hughes ES, McDermott FT, et al. A comparison of end-toend staple and suture colorectal anastomosis in the dog. Surg Gynecol Obstet. 1981;152:792-796.

6. Brower RA, Freeman LD. Balloon catheter dilation of a rectal stricture. Gastrointest Endosc. 1984;30:95-97

7. Virgilio C, Cosentino S, Favara C, et al. Endoscopic treatment of postoperative colonic strictures using an achalasia dilator: shortterm and long-term results. Endoscopy. 1995;27:219-222.

8. Kimmey MB, Al-Kawas FH, Gannan RM, Saeed ZA, Carr-Locke DL, Edmundowicz SA, et al. Technology assessment status evaluation: balloon dilation of gastrointestinal tract strictures. Gastrointest Endosc 1995;42:608-11.

9. Werre A, Mulder C, Van Heteren C, Bilgen ES. Dilation of benign strictures following low anterior resection using Savary-Gilliard bougies. Endoscopy 2000;32:385-8

10. Pietropaolo V, Masoni L, Ferrara M, Montori A. Endoscopic dilation of colonic postoperative strictures. Surg Endosc 1990;4:26-30.

11. Aston NO, Owen WJ, Irving JD. Endoscopic balloon dilatation of colonic anastomotic strictures. Br J Surg 1989;76:780-2.

12. Venkatesh KS, Ramanujam PS, McGee S. Hydrostatic balloon dilatation of benign colonic anastomotic strictures. Dis Colon Rectum 1992;35:789-91.

13. Dinneen MD, Motson RW. Treatment of colonic anastomotic strictures with "through the scope" balloon dilators. J R Soc Med 1991;84:264-6.

14. Fregonese D, Di Falco G, Di Toma F. Balloon dilatation of anastomotic intestinal stenoses: long-term results. Endoscopy 1990;22:249-53.

15. Hagiwara A, Sakakura C, Shirasu M, Torii T, Hirata Y, Yamagishi H. Sigmoidofiberscopic incision plus balloon dilatation for anastomotic cicatricial stricture after anterior resection of the rectum. World J Surg 1999;23:717-20.

16. Luck A, Chapuis P, Sinclair G, Hood J. Endoscopic laser stricturotomy and balloon dilatation for benign colorectal strictures. ANZ J Surg 2001;71:594-7.

17. Brandimarte G, Tursi A, Gasbarrini G. Endoscopic treatment of benign anastomotic colorectal stenosis with electrocautery.Endoscopy 2000;32:461-3.

18. M. Albertsmeier et al.Treatment of a completely obstructed colonic anastomotic stricture using a CT-guided endoscopic rendezvous technique. Endoscopy. 2011;43 Suppl 2:E5-6. Epub 2011 Jan 26

19. Curcio G et al. Completely obstructed colorectal anastomosis: a new non-electrosurgicaloscopic approach before balloon dilatation. World J Gastroenterol. 2010 Oct 7;16(37):4751-4

20. Di Giorgio P, De Luca L, Rivellini G et al. Endoscopic dilation of benign colorectal anastomotic stricture after low anterior resection: A prospective comparison study of two balloon types. Gastrointest Endosc. 2004 Sep;60(3):347-50.

21. Delaunay-Tardy K, Barthélémy C, Dumas O, Balique JG, Audigier JC. Endoscopic therapy of benign colonic post-operative strictures: report on 27 cases. Gastroenterol Clin Biol. 2003 Jun;27(6-7):610-3 